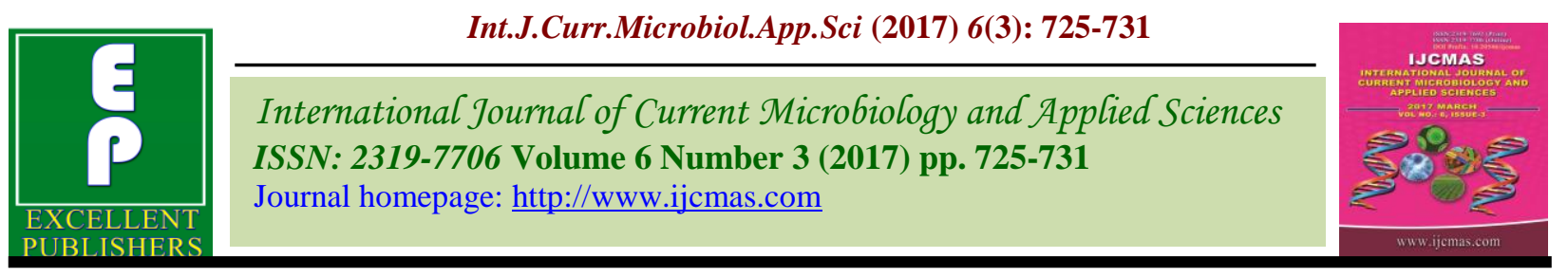

Original Research Article

https://doi.org/10.20546/ijcmas.2017.603.084

\title{
Evaluation of Antimicrobial Potential of Juices of Some Common Citrus and Non-Citrus Fruits of India
}

\section{Ashim Kumar Basak ${ }^{1 *}$, Tridip Chatterjee ${ }^{1}$, Debashis Majumder ${ }^{2}$, Syed Zunaid Hussain², Suman Mallick ${ }^{2}$ and Amit Chakravarty ${ }^{3}$}

\author{
${ }^{1}$ Department of Molecular Biology, ${ }^{2}$ Department of Biotechnology, \\ ${ }^{3}$ Institute of Genetic Engineering, 30 Thakurhat Road, Kolkata 700128, India \\ *Corresponding author
}

\author{
A B S T R A C T
}

\section{Keywords \\ Antimicrobial, resistance, juices, microorganism, zone of inhibition (ZOI), Citrus, phytochemical.}

Article Info

Accepted:

15 February 2017

Available Online:

10 March 2017
Worldwide indiscriminate uses of antibiotics to control pathogenic bacteria have led to the spread of the resistant strains of microorganisms making treatment of bacterial infections by these drugs difficult. Thus scientists are in search of safe alternative therapies against these dangerous and even life threatening pathogens. Plants produce many phytochemicals having antimicrobial properties. These may be used as natural drugs which are generally nontoxic and less expensive than the synthetic drugs. In this present study, with the help of agar well diffusion method, an attempt was made to find out antimicrobial properties of the juices of some common edible Citrus and non Citrus fruits against five pathogenic bacteria. It was observed that $E$. coli was the only bacteria that was inhibited by all fruit juices. Citrus fruit juices appeared to be more efficient than non Citrus fruits in inhibiting microorganisms as they created larger zones of inhibitions in agar plates inoculated with bacterial species both in crude and diluted state. Among the all fruit juices tested, lemon juice was the most efficient that inhibited all five bacteria equally well both in crude and diluted states. Limited qualitative phytochemical analysis of fruit juices revealed that the juice of the Citrus fruit carambola contained majority, i.e. three out four phytochemicals tested. Results of our study indicated that Citrus fruits act as very potent natural antibacterial agents and may act as cheap resources of prophylaxis against potential pathogenic microorganisms for the benefit of the people of developing world where huge medical cost is a burden in the societies.

\section{Introduction}

Antibiotics, since their introductions in medicine during 1940s, have saved millions of lives by treating serious infections, preventing infections in surgical patients, protecting cancer patients under chemotherapy, using as prophylaxis to weakened immune system and so on (Ventola, 2015; CDDEP, 2015). Although medical applications have improved the life expectancy in human (DHD Europe, 2011), many disease causing bacteria nowadays have become resistant to antibiotic therapy making the treatments of these diseases difficult (Kenneth, 2015). Bacteria exhibit antibiotic resistance by employnig several mechanisms like enzymatic inactivation of antibiotics, preventing antibiotics from entering the cells or effluxing them, altering the target sites of action of the antibiotic or bypassing the effect of antibiotics by producing alternative targets 
of antibiotics (Hawke, 1998; Blair et al., 2015). Owing to abuse or overuse of antibiotics in recent times in medicine, animal care and agriculture higher levels of antibiotic resistant bacteria have been resulted (Bansode and Chavan, 2013). Everytime, owing to intake of antibiotic, susceptible bacteria are killed but resistant bacteria survive and multiply due to the possession of resistant genes in them. Even the bacteria which were once susceptible to a particular antibiotic may become resistant by acquiring gene mutations or receiving resistant gene through horizontal gene transfer (Blair et al., 2015, RXLIST, 2016). Thus worldwide resistance of pathogens to antibiotics has now provided an impetus to find out safe and effective alternative therapies to infection which are difficult to handle due to the activities of resistant bacteria. Plants for a long time are known to have significant source of natural products having antioxidant, antitumor, antimutagenic and antimicrobial properties and confer substantial health benefits by providing protections against many diseases including cardiovascular diseases, certain types of cancer etc. It is considered that antimicrobial activities of medicinal plants are due to the presence of phytochemicals, mostly secondary metabolites like phenol, flavonoids, tarpenoids, alkaloids etc in them (Compean and Ynalvez, 2014; Das, 2012; Cowan, 1999). Fruits are an important part of human diet that provides essential nutrients as well as many bioactive compounds like vitamins and secondary metabolites for promotion of health and prevention of diseases (Liu, 2013). Recently immense interests among the scientists have grown to find the antimicrobial properties of fruits of human consumption (Bansode and Chavan, 2013; Das, 2012; Manzoor, 2013; Philip et al., 2012; Rahman et al., 2015; Khan and Hanee, 2011).

In this present study an attempt was made to investigate the antimicrobial activities of the juices of some edible Citrus and non Citrus fruits against some medically important gram positive and gram negative bacteria. Furthermore we also analyzed a limited number of phytochemicals in these juices which are reported to have anti-infective properties (Cowan, 1999).

\section{Materials and Methods}

\section{Preparation of fruit juices}

Three fresh Citrus fruits namely- lemon (Citrus limon), amla (Phyllanthus emblica) and carambola (Averrhoa carambola) and four nonCitrus fruitsnamely- pomegranate (Punica granatum), sapodilla (Manilkara zapota), grape (Vitis vinifera) and Cherry (Prunus avium) were purchased from local market. All the fruits were washed with running tap water followed by sterilization of their surfaces with $70 \%$ alcohol and later were rinsed with sterile distilled water. Surfaces of the fruits were wiped with sterile cotton and dried at room temperature. Edible parts of the fruits were squeezed under sterile condition to collect juices. $50 \%$ dilute fruit juices were prepared by mixing crude juices of the fruits with sterile distilled water in 1:1 ratio.

\section{Determination of antimicrobial activities of fruit juices}

Cultures of three gram negative bacteria namely- Escherichia coli, Pseudomonas aeruginosa and Klebsiella sp. as well as two gram positive bacteria namelyStaphylococcus aureus and Bacillus subtilis were obtained from the institutional microbiology laboratory and were stored in a refrigerator. Antimicrobial properties of fresh fruit juices were evaluated by agar well diffusion method. Briefly, petriplates containing nutrient medium composed of peptone, beef extract, sodium chloride, agar and distilled water were prepared for the 
evaluation of antimicrobial activities of fruit juices. 100 $\mu \mathrm{l}$ of inoculum of each bacterium under our study was uniformly spreaded on the nutrient agar lawn in separate petriplates with the help of a sterilized glass spreader and the plates were then incubated for 30 minutes in the room temperature inside a laminar hood. Following this, with the help of a sterile cork, wells having the diameter of $6 \mathrm{~mm}$ were bored in the plates. $60 \mu \mathrm{l}$ of fresh crude and diluted fruit juice samples, distilled water and aqueous solution of antibiotic ampicillin $(2.5 \mathrm{mg} / \mathrm{ml})$ were poured separately into the wells. Distilled water and ampicillin solution acted as negative and positive controls respectively. After 10 minutes of incubation at room temperature all the plates were transferred to an incubator and kept inside it at $37^{\circ} \mathrm{C}$ for 24 hours. Following the incubation, plates were checked for the presence of zones of inhibition (ZOI). Diameters of the observed ZOIs were measured in $\mathrm{mm}$ and the results were recorded by taking photographs of the ZOIs on the plates.

\section{Phytochemical analysis of fruit juices}

Qualitative analyses of limited number of bioactive compound namely- flavonoids, saponin, glycoside, steroid in fruit juices were done according to standard methods (Bansode and Chavan, 2013).

\section{Results and Discussion}

Results of our study showed that juices of all seven fruits exhibited inhibitory actions against the bacterium E. coli. B. subtilis and $S$. aureus were inhibited by six and four fruit juices respectively. Inhibition of other two bacteria by the number of fruit juices could not be determined as inhibition of this bacteria were not tested by grape and cherry juices. Table 1 and table 2 show the diameters (in $\mathrm{mm}$ ) of zones of inhibitions (ZOI) created in the agar plate by crude (100\%) and diluted
(50\%) juices of three Citrus and two non Citrus fruits respectively. Inhibitory activities of juices of other two non Citrus fruits are tabulated separately in table 3 as lesser number of bacteria were tested to assess the inhibitory activities of these fruit juices. It appeared from our study that one Citrus fruit and one non Citrus fruit namely -lemon and pomegranate exhibited inhibitory actions against all the bacteria tested in our study. Amla also exhibited inhibitory action against all bacterial species except for B.subtilis. Carambola, another Citrus fruit exhibited its inhibitory activities against as many as 3 bacterial species except for P.aeruginosa and Klebsiella $s p$. It is to be noted that antibacterial potentials exhibited by Citrus fruit juices remained active both in their crude and diluted conditions. Although crude juice of pomegranate exerted inhibitory actions against all the bacteria, could only inhibit Klebsiella sp., S. aureus and B. subtilis in its diluted state. Sapodilla juice, however, showed appreciable inhibitory potential both in crude and in diluted form against $E$. coli and B. Subtilis but failed to inhibit other three bacteria (Tables 1 and 2). Both grape and cherry juices could inhibit $E$. coli and $B$. subtilis. Although cherry juices could inhibit these bacteria both in crude and diluted states, diluted grape juice failed to do so (Table 3 ).

Overall, in terms of extent of the increasing ZOIs, it appears that Citrus fruits exhibited better inhibitory activities against pathogens than non Citrus fruits. Crude juice of lemon showed maximum inhibitory effects having the diameters of ZIOs of $20 \mathrm{~mm}, 18 \mathrm{~mm}$, $18 \mathrm{~mm}, 16 \mathrm{~mm}$ and $14 \mathrm{~mm}$ against $B$. subtilis, $S$. aureuss, E. coli, $P$. aeruginosa and Klebsiella sp. respectively. Although carambola could not inhibit the growth of $P$. aeruginosa and Klebsiella sp., its inhibitory effects were appreciable having ZOIs of $16 \mathrm{~mm}, 16 \mathrm{~mm}$ and $15 \mathrm{~mm}$ in diameters against E. coli, S. aureus and B. subtilis respectively. 
Among the non Citrus fruit juices pomegranate appeared to be most effective as it inhibited all bacteria in its crude form and three bacteria its diluted state. However, in general, diameters of ZOIs exhibited by pomegranate juice appeared to be smaller than the Citrus fruits. Sapodilla juice, on the other hand, with regard to diameter of ZOIs, showed appreciable inhibitory potential both in crude and in diluted form against $E$. coli and $B$. Subtilis but failed to inhibit other three bacteria. Diameters of ZOIs exhibited by grape and cherry juices were moderate in sizes. ZOIs on nutrient agar plate created by some fruit juices in their crude $(100 \%)$ and diluted $(50 \%)$ states against some of the bacteria have been shown in Fig1.

Limited number of phytochemical analysis (Table 4) revealed that flavonoids and saponin were of major occurrences among the fruit juices. Caramabola juice exhibited the presence of maximum numbers of phytochemicals i.e. 3 out of 4 tested. Majority of other fruit juices contained only 2 phytochemicals. Cherry contained only one phytochemical i.e. glycoside.

In this present study an attempt had been made to appraise the antimicrobial potential of some common Citrus and non Citrus fruits against some pathologically important bacteria which might cause serious health hazards in human. For example, E. coli, a normal intestinal flora in human, can cause gastroenteritis, urinary tract infections, and neonatal meningitis etc (Bachir raho and Abouni, 2015). Klebsiella can cause pneumonia, meningitis, blood stream infection (NIH National Center for Advancing translational Sciences, 2014); P. aeruginosa may be responsible for nosocomial infection, pneumonia, bacteraemia, diarrhoea etc (Chen,
2016) and S.aureus can cause skin infection, pneumonia, bacteremia and food poisoning (Bachir raho and Abouni, 2015). Although $B$. subtillis is not considered harmful to human but it was assigned to have the potentiality of causing hepatoxicity (Probiotic.org, 2016) and as well as causing septicaemia in immune compromised patients when this bacteria was used as probiotic (Oggioni et al., 1998).

Among the seven fruit juices tested, Citrus fruits juices proved to be more efficient in inhibiting bacterial growth as they worked well both in their crude and diluted states. In addition, ZOIs created by the Citrus fruit juices were larger in diameter than those were created by non Citrus fruits. In contrast some non Citrus fruit juices lacked the inhibitory potential at their diluted states Moreover, ZOIs created by non-Citrus fruits were mainly moderate in sizes.

From very beginning of the human civilization plants had been used for treating diseases and many plants are now used in traditional medicine as medicinal plants (Khan and Hanee, 2011). It is well known that diets rich in fruits and vegetables afford substantial health benefits by providing protections against a number of diseases (Das, 2012).

The main advantage of plant derived natural drugs are that they are generally non-toxic to human beings and are less expensive compared to synthetic drugs (Anatharackal, 2011). Citrus fruit are reported to have wide range of vitamins, minerals and phytochemicals that have shown beneficial effects in human epidemiological studies, in cellular and animal experiments (Baghurst, 2003). 
Table.1 Antibacterial screening of three citrus fruit juices

\begin{tabular}{|l|c|c|c|c|c|c|}
\hline \multirow{2}{*}{ Microorganisms } & \multicolumn{5}{|c|}{ Diameters of zones of Inhibition (in mm) } \\
\cline { 2 - 7 } & $\begin{array}{c}\text { Lemon } \\
\begin{array}{c}\text { Crude } \\
\text { juice } \\
(100 \%)\end{array}\end{array}$ & $\begin{array}{c}\text { Diluted Juice } \\
(50 \%)\end{array}$ & $\begin{array}{c}\text { Crude } \\
\text { juice } \\
(100 \%)\end{array}$ & $\begin{array}{c}\text { Diluted } \\
\text { Juice } \\
(50 \%)\end{array}$ & $\begin{array}{c}\text { Crude } \\
\text { juice } \\
(100 \%)\end{array}$ & $\begin{array}{c}\text { Diluted } \\
\text { Juice } \\
(50 \%)\end{array}$ \\
\hline E. coli & 18 & 16 & 14 & 12 & 16 & 14 \\
\hline P. aeruginosa & 16 & 15 & 12 & 10 & - & - \\
\hline Klebsiella sp. & 14 & 12 & 14 & 12 & - & - \\
\hline S. aureus & 18 & 17 & 13 & 12 & 16 & 12 \\
\hline B. subtilis & 20 & 19 & - & - & 15 & 13 \\
\hline
\end{tabular}

Table.2 Antibacterial screening of juices of two non citrus fruits -pomegranate and sapodilla

\begin{tabular}{|l|c|c|c|c|}
\hline \multirow{2}{*}{ Microorganisms } & \multicolumn{4}{|c|}{ Diameters of zones of Inhibition (in mm) } \\
\cline { 2 - 5 } & \multicolumn{2}{|c|}{ Pomgranate } & \multicolumn{2}{c|}{ Sapodilla } \\
\cline { 2 - 5 } & $\begin{array}{c}\text { Crude juice } \\
(100 \%)\end{array}$ & $\begin{array}{c}\text { Diluted Juice } \\
(50 \%)\end{array}$ & $\begin{array}{c}\text { Crude juice } \\
(100 \%)\end{array}$ & Diluted Juice (50\%) \\
\hline E. coli & 8 & - & 14 & 11 \\
\hline P. aeruginosa & 8 & - & - & - \\
\hline Klebsiella $s p$. & 10 & 8 & - & - \\
\hline S. aureus & 10 & 9 & - & 12 \\
\hline B. subtilis & 15 & 14 & 14 & - \\
\hline
\end{tabular}

Table.3 Antibacterial screening of juices of two non citrus fruits - grape and cherry

\begin{tabular}{|l|c|c|c|c|}
\hline \multirow{2}{*}{ Microorganisms } & \multicolumn{3}{|c|}{ Diameters of zones of Inhibition (in mm) } \\
\cline { 2 - 5 } & \multicolumn{3}{|c|}{ Grape } & Cherry \\
\cline { 2 - 5 } & Crude juice (100\%) & $\begin{array}{c}\text { Diluted Juice } \\
(50 \%)\end{array}$ & $\begin{array}{c}\text { Crude juice } \\
(100 \%)\end{array}$ & Diluted Juice (50\%) \\
\hline E. coli & 10 & - & 8 & 8 \\
\hline S.aureus & - & - & - & - \\
\hline B. subtilis & 10 & - & 9 & 8 \\
\hline
\end{tabular}

Table.4 Phytochemical constituents of fruit juices

\begin{tabular}{|l|c|c|c|c|}
\hline Fruit juices & Flavonoids & Saponin & Steroid & Glycoside \\
\hline Lemon & + & + & & \\
\hline Amla & - & + & - & + \\
\hline Carambola & + & + & - & + \\
\hline Pomgranate & + & - & + & - \\
\hline Sabeda & + & + & - & - \\
\hline Grape & + & + & - & - \\
\hline Cherry & - & - & - & + \\
\hline
\end{tabular}


Fig.1 Showing ZOIs on nutrient agar plate created by some fruit juices in their crude (100\%) and diluted $(50 \%)$ states against some of the bacteria. (Legend: Plate A=Antibacterial activity of lemon juice on $E$. coli; Plate $\mathrm{B}=$ Antibacterial activity of carambola and amla juices on E. coli; Plate $\mathrm{C}=$ Antibacterial activity of carambola and amla juices on S.aureus; Plate $\mathrm{D}=$ Antibacterial activity of cherry juice on $E$. coli; Plate $\mathrm{E}=$ Antibacterial activity of cherry juice on B. subtilis; Plate $\mathrm{F}=$ Antibacterial activity of lemon juice on S.aureus; Plate $\mathrm{G}=$ Antibacterial activity of Pomegranate juice on S.aureus; Plate $\mathrm{H}=$ Antibacterial activity of Sapodilla juice on B.subtilis).

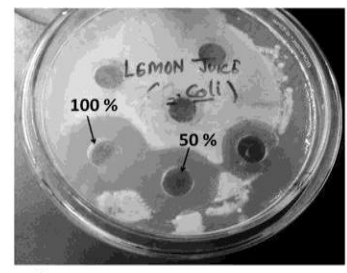

A

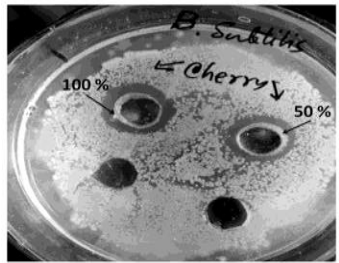

$\mathbf{E}$

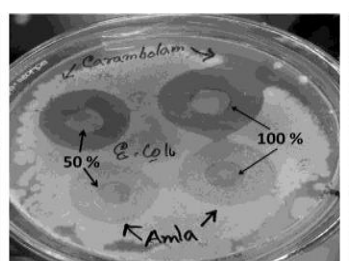

B

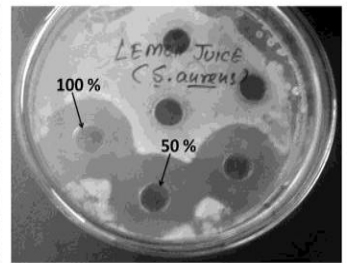

F

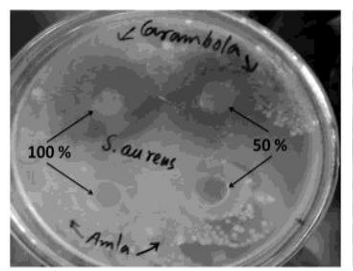

C

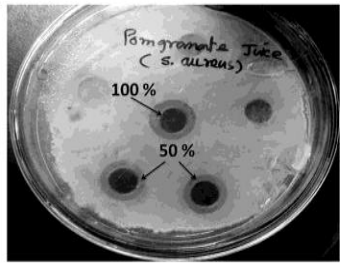

G

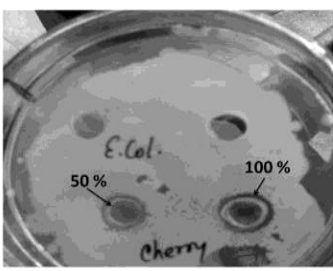

D

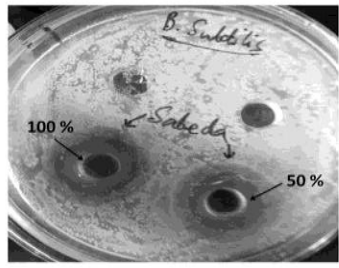

H

In our present study, carambola, a Citrus fruit showed the presence of three out of four phytochemicals analyzed. As we have qualitatively analyzed the presence of only a few number of phytochemicals in the fruit juices, additional analyses are needed to decipher the presences of some more phytocomponents in them. According to the results obtained from our study, it can be predicted that owing to the challenges of growing antibiotic resistances demonstrated by pathogens that infect human beings, regular consumption of Citrus fruits in diet may offer prophylaxis against these infectious agents. According to a report made by World Health Organization (WHO), 60-90\% of the population in developing world relies on the traditional medicines as primary health care of which herbal medicines comprise a substantial part (WHO, 2002). Citrus fruits are cheap and easily available. Owing to their appreciable antimicrobial properties, as revealed by our study, regular dietary uses of Citrus fruits may provide sufficient prophylaxis against potential infectious agents to the people of developing countries including India where a major portion of people are poverty-stricken and huge burden of medical cost accelerating the poverty further (Balarajan et al., 2011).

\section{Acknowledgments}

We express our thanks to Dr. Paramita Gangopadhyay Bhattacharya, Head of the Department of Microbiology, Institute of Genetic engineering, for her suggestion. We also acknowledge our thanks to Debalina Laha and Srishti Mondal, students of Institute of Genetic Engineering for their occasional participations in the work.

\section{References}

Anatharackal, G.S., Benny, P.V., Kuriakose, S., George, C. 2011. Antibiotic activity of 2, 3dihydroxybenzoic acid isolated from Flacourtia inermis fruit against multidrug resistant bacteria, Asian J. Pharma Clin. Res., 4(1): 126-130.

Bachir raho, G., Abouni, B. 2015. The Battle Against Microbial Pathogens: Basic Science, Technological Advances and Educational Programs (Vol 2. Extremadura: Formatex Research Center.

Baghurst, K. 2003. The health benefits of citrus fruits, CSIRO Health Sciences \&Nutrition Project Number: CT02057 Horticultural Australia Ltd. 
Balarajan, Y., Selvaraj, S., Subramanian, S.V. 2011. Health care and equity in India, Lancet, 377(9764): 505-515.

Bansode, D.S., Chavan, M.D. 2013. Evaluation of antimicrobial activity and phytochemical analysis of papaya and pineapple fruit juices against selected enteric pathogens. Int. J. Pharm. Bio. Sci., 4(2): 1176-1184.

Blair, J.M.A., Webber, M.A., Baylay, A.J., Ogbolu, D.O., Piddock, L.J.V. 2015. Molecular mechanisms of antibiotic resistance. Nat. Rev. Microbiol., 13(1): 4251.

Bulletin of DHD Europe 1td. 2011. Part 3: The introduction of antibiotics rapidly extends life expectancy.

Center for Disease Dynamics, Economics \& Policy. 2015. State of the World's Antibiotics, CDDEP: Washington, D.C.

Chen, S.S.P. 2016. Pseudomonas Infection Clinical Presentation, Medscape, Probiotic.org Newsletter, Bacillus subtilis.

Cowan, M.M. 1999. Plant Products as Antimicrobial Agents. Clin. Microbiol. Rev., 12(4): 564-582.

Das, S. 2012. Antimicrobial and antioxidant activities of green and ripe fruits of Averrhoa carambola Linn. and Zizyphus mauritiana Lam. Asian J. Pharm. Clin. Res., 5(3): 102-105.

Hawkey, P.M. 1998. The origins and molecular basis of antibiotic resistance. BMJ, 317(7159): 657-660.

Khan, J.A., Hanee, S. 2011. Antibacterial properties of Punica granatum peels, Int. J. Appl. Biol. Pharma Tech., 2(3): 23-27.

Liu, R.H. 2013. Health-promoting components of fruits and vegetables in the diet. Adv. Nutr.,
4(3): 384S-92S. doi: 10.3945/an.112.003517.

Manzoor, M., Naseer, S., Jabeen, R., Manzoor M. 2013. Antibacterial activity of fruits against Escherichia coli. ARPN J. Agr. Biol. Sci., 8(3): 258-263.

NIH National Center for Advancing translational Sciences. 2014. Klebsiella infection.

Oggioni, M.R., Pozzi, G., Valensin, P.E., Galieni, P., Bigazz, C. 1998. Recurrent septicemia in an immunocompromised patient due to probiotic strains of Bacillus subtilis, J. Clin. Microbiol., 6(1): 325-326.

Philip, J., John, S., Iyer, P. 2012. Antimicrobial activity of Aloevera barbedensis, Daucus carota, Emblica officinalis, Honey and Punica granatum and Formulation of a Health Drink and Salad. Malaysian $J$. Microbiol., 8(3): 141-147.

Rahman, M.M., Ali, M.Y., Mondal, S.I., Hoque, M.M. 2015. Evaluation of antimicrobial properties of some local fruits of Bangladesh, Int. Food Res. J., 22(2): 854858.

RXLIST Inc. 2016. Antibiotic Resistance Compean, K.L., Ynalvez, R.A. 2014. Antimicrobial activity of plant secondary metabolites: A review. Res. J. Med. Plant, 8(5): 204-213.

Todar, K. 2008. Bacterial Resistance to Antibiotics, Todar's Online Textbook of Bacteriology.

Ventola, C.L. 2015. The antibiotic resistance crisis. Part 1: Causes and Threats. Pharm. Therap., 40(4): 277-283.

WHO. 2002. Traditional medicine Growing Needs and Potential. WHO Policy Perspectives on Medicines. Geneva: World Health Organization.

\section{How to cite this article:}

Ashim Kumar Basak, Tridip Chatterjee, Debashis Majumder, Syed Zunaid Hussain, Suman Mallick, Amit Chakravarty. 2017. Evaluation of Antimicrobial Potential of Juices of Some common Citrus and Non-Citrus Fruits of India. Int.J.Curr.Microbiol.App.Sci. 6(3): 725-731. doi: https://doi.org/10.20546/ijcmas.2017.603.084 